\title{
Differential involvement of amygdala and cortical NMDA receptors activation upon encoding in odor fear memory
}

\author{
Chloé Hegoburu, ${ }^{1}$ Sandrine Parrot, ${ }^{1}$ Guillaume Ferreira, ${ }^{2,3}$ and Anne-Marie Mouly ${ }^{1}$ \\ ${ }^{1}$ Centre de Recherche en Neurosciences de Lyon, INSERM U1028, CNRS UMR5292, University Lyon1, Lyon, France; ${ }^{2}$ INRA, \\ Nutrition et Neurobiologie Intégrée, UMR 1286, Bordeaux, France; ${ }^{3}$ Université de Bordeaux, Nutrition et Neurobiologie \\ Intégrée, Bordeaux, France
}

\begin{abstract}
Although the basolateral amygdala (BLA) plays a crucial role for the acquisition of fear memories, sensory cortices are involved in their long-term storage in rats. However, the time course of their respective involvement has received little investigation. Here we assessed the role of the glutamatergic $N$-methyl-D-aspartate (NMDA) receptors in the BLA and olfactory cortex at discrete moments of an odor fear conditioning session. We showed that NMDA receptors in BLA are critically involved in odor fear acquisition during the first association but not during the next ones. In the cortex, NMDA receptor activation at encoding is not necessary for recent odor fear memory while its role in remote memory storage needs further investigation.
\end{abstract}

Although the amygdala plays a crucial role for the acquisition and storage of fear memories (for review, see LeDoux 2000; Maren 2001; Gale et al. 2004), sensory cortices were also shown to be involved in the long-term storage of the sensory attributes of remote fear memories in rats (Sacco and Sacchetti 2010). However, the precise time course of amygdala and sensory cortices involvement in fear conditioning remains to be clearly identified. In a recent study investigating hippocampal-cortical interactions, Lesburguères et al. (2011) showed that neurons in the rat cortex undergo a "tagging process" upon encoding to ensure the progressive rewiring of cortical networks that support remote memory storage. We reasoned that the same phenomenon might occur in amygdala-dependent memories and that the amygdala and cortical networks might be involved together at the time of encoding in order for fear memories to be stored in the long term.

In a previous study using odor fear conditioning, we compared the dynamics of glutamate fluctuations between basolateral amygdala (BLA) and olfactory cortex (posterior piriform cortex: pPC) during the acquisition session (Hegoburu et al. 2009). In the BLA, we observed a transient increase in glutamate in response to the first odor-shock pairing only, whereas in the pPC increases in glutamate were seen after each pairing of the acquisition session. This led us to hypothesize that two parallel processes take place at encoding: the BLA might be critically involved early and transiently to encode unexpected stimulus-danger association; in parallel via a glutamatergic projection pathway, the BLA would trigger the involvement of the $\mathrm{pPC}$ which might be engaged regularly throughout the session to progressively build up the long-term engram as suggested by the literature (Sacco and Sacchetti 2010; Lesburguères et al. 2011). Because N-methyl-D-aspartate (NMDA) receptors play a major role in memory processes (for review, see Riedel et al. 2003), in this study we manipulated NMDA receptors in either the BLA or the pPC, at discrete moments of the acquisition session. We predicted that blocking NMDA receptors in the BLA before odor-shock training would prevent learning, while delaying the blockade to after the first

\section{Corresponding author: annemarie.mouly@cnrs.fr}

Article is online at http://www.learnmem.org/cgi/doi/10.1101/lm.036558.114. pairing would not. In contrast, blocking NMDA receptors in the pPC before training should not alter recent memory but should compromise its remote storage.

We first assessed the effects of the injection of the NMDA antagonist AP5 (D,L-2-amino-5-phosphonovaleric acid) in the BLA either before or after the first odor-shock association, on the animal's performance $24 \mathrm{~h}$ later. Adult Long-Evans male rats (Janvier, France; 250-300 g) were housed individually and maintained under a 12-h light-dark cycle with ad libitum access to food and water. All experiments and surgical procedures were conducted in accordance with the European Community Council Directive (86/609/EEC) and the French National Committee $(87 / 848)$ for care and use of laboratory animals. Forty-two animals were implanted bilaterally with 23 -gauge guide cannulae positioned $2 \mathrm{~mm}$ above the BLA (AP $+2.8 \mathrm{~mm}$ relative to bregma; $\mathrm{ML}+4.9 \mathrm{~mm}$; DV $-5.2 \mathrm{~mm}$ from dura). Injection needles (30 gauge, extending $2 \mathrm{~mm}$ from the tip of the guide cannula) connected to a microinfusion pump (Harvard Apparatus) allowed the infusion of AP5 (Sigma-Aldrich; $2.5 \mu \mathrm{g} / 0.5 \mu \mathrm{L}, 0.5 \mu \mathrm{L}$ per hemisphere). After 1 wk of recovery from the surgery, the animals were trained in an olfactory fear conditioning paradigm (Sevelinges et al. 2004; Hegoburu et al. 2009). Briefly, the animal received six pairings of $20 \mathrm{sec}$ peppermint odor coterminating with a 1 -sec footshock $(0.4 \mathrm{~mA})$ using a 4-min intertrial interval (total session duration: $28 \mathrm{~min}$ ). The conditioned fear was assessed $24 \mathrm{~h}$ later, by presenting the peppermint odor four times for $20 \mathrm{sec}$ with a 1-min intertrial interval (total session duration: $6 \mathrm{~min})$. During the different phases of the experiment, the animal's freezing behavior was videotaped for offline analysis (Hegoburu et al. 2011). During acquisition, post-shock freezing was measured and expressed as a percentage of the whole session duration (except the 4-min acclimation period preceding the first pairing). During the 24-h retention test, the amount of freezing

(C) 2014 Hegoburu et al. This article is distributed exclusively by Cold Spring Harbor Laboratory Press for the first 12 months after the full-issue publication date (see http://learnmem.cshlp.org/site/misc/terms.xhtml). After 12 months, it is available under a Creative Commons License (AttributionNonCommercial 4.0 International), as described at http://creativecommons .org/licenses/by-nc/4.0/. 
during the $2 \mathrm{~min}$ before odor introduction (Pre-Odor Period) was compared with the first minute of odor presentation (Odor Period). Analysis of variance (ANOVA) with repeated measures followed by Fisher post hoc tests was used. Significance was taken at $P \leq 0.05$.

The experimental groups were divided into six categories. In the 6_Pre groups, AP5 (6_Pre AP5, $n=7$ ) or NaCl (6_Pre NaCl, $n=$ 7) was infused in the BLA 1 min prior to the conditioning session that included six odor-shock pairings. In the 6_Post groups, AP5 (6_Post AP5, $n=7$ ) or $\mathrm{NaCl}$ (6_Post $\mathrm{NaCl}, n=7$ ) was infused $3 \mathrm{~min}$ after the first pairing of the training session. In the 1_Post groups, the conditioning session included only one odor-shock pairing and AP5 (1_Post AP5, $n=7$ ) or $\mathrm{NaCl}$ (1_Post NaCl, $n=7$ ) was infused $3 \mathrm{~min}$ after the pairing. In all the groups, the animals remained tethered to the infusion tubing throughout training. Retention was assessed $24 \mathrm{~h}$ after the conditioning session. Figure 1A illustrates the injection cannulae placements in BLA in the six experimental groups. During acquisition, the level of post-shock freezing was similar in the six experimental groups $\left(F_{(5,36)}=1.2, P=0.33\right.$; Fig. 1B). For the 24 -h retention test, we carried out a three-factor mixed ANOVA, with the Drug (AP5 versus $\mathrm{NaCl}$ ) and the Time of infusion (Pre- versus Post-first pairing) as independent factors, and the Period (Pre-Odor versus Odor) as repeated measures. The comparison of the four groups with six odor-shock pairings (6_Pre and 6_Post) revealed a significant effect of Drug $\left(F_{(1,24)}=10.25, P=0.004\right)$, Period $\left(F_{(1,24)}=55.83, P<0.001\right)$, and Drug $\times$ Time of infusion $\times$ Period interaction $\left(F_{(1,24)}=4.8, P=0.038\right)$. Post hoc analyses showed that all the groups except the 6_Pre AP5 group presented a significant increase in freezing in response to the learned odor compared with preodor levels (see Fig. 1C for the $P$ values). Comparison of the 6_Post groups with the 1_Post groups revealed a significant effect of Number of pairings (6 versus $\left.1 ; F_{(1,24)}=4.41 ; P=0.046\right)$, Period $\left(F_{(1,24)}=39.17 ; \quad P<0.001\right)$, and Number of pairings $\times$ Period interaction $\left(F_{(1,24)}=7.64 ; P=0.011\right)$, but no effect of Drug. Post hoc comparisons showed that while freezing increased significantly in response to the learned odor in the 6_Post groups, the increase did not reach significance in the 1_Post groups (Fig. 1C). In summary, these data show that AP5 infused in the BLA pretraining prevented fear memory acquisition. In contrast, when AP5 was infused after the first pairing, learning was not impaired, and was higher than that observed with only one pairing.

We then assessed the functionality of the glutamatergic amygdalo-piriform pathway by measuring the impact of an artificial increase of glutamate in the BLA on glutamate levels in the pPC via high temporal resolution microdialysis (Parrot et al. 2004). Twelve animals were included in this experiment carried out on anesthetized animals (urethane, $1.4 \mathrm{~g} / \mathrm{kg}, 0.5 \mathrm{~mL} / 100 \mathrm{~g}$, i.p.). For six animals, an injection cannula and a microdialysis probe were implanted in the

\section{A}

B
BLA (AP $-2.8 \mathrm{~mm}$; $\mathrm{ML}+4.9 \mathrm{~mm}$; DV $-7.5 \mathrm{~mm}$ from dura). In the other six, the injection cannula was implanted in the BLA, while the microdialysis probe was implanted in the ipsilateral pPC (AP $-1.8 \mathrm{~mm}$; ML $+5.5 \mathrm{~mm}$; DV $-8.2 \mathrm{~mm}$ from dura). The microdialysis sampling procedure has been described previously (Bert et al. 2002; Hegoburu et al. 2009). Briefly, sampling (1 $\mu \mathrm{L} /$ min) started $3 \mathrm{~h}$ after the probe/injection cannula implantation. The first four samples constituted the baseline level. Then the first infusion of the glutamate uptake inhibitor PDC (L-trans-pyrrolidine-2,4-dicarboxylic acid, $0.3 \mu \mathrm{L}$ at $2 \mu \mathrm{L} / \mathrm{min}$; Tocris Bioscience) was delivered followed by a second infusion $8 \mathrm{~min}$ later. The samples were then analyzed for glutamate content using capillary electrophoresis coupled to a laser-induced fluorescence detector as previously described (Hegoburu et al. 2009). Figure 2A illustrates the placement of the microdialysis probes in the BLA and pPC, as well as the PDC infusion sites in BLA. As expected PDC infusion in BLA increased glutamate levels locally, reaching 400\%$600 \%$ of the baseline concentration from the start of the infusion to $4-5$ min after $\left(F_{(25,125)}=4.6, P<0.0001\right.$; Fig. $2 \mathrm{~B}$, upper part). Each infusion of PDC in BLA also induced a significant increase of glutamate levels in $\mathrm{pPC}\left(F_{(25,75)}=1.7, P=0.044\right.$; Fig. 3B, lower part), in particular 1 and 5 min after the first infusion, and 2 min after the second one $(P<0.05)$. For both infusions, the increase in glutamate was delayed for 1 or 2 min in pPC compared with BLA.

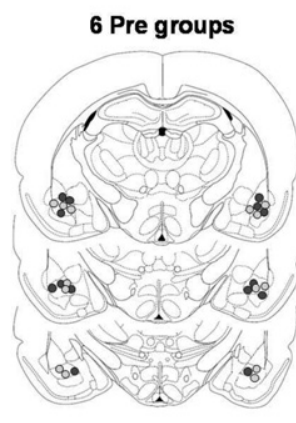

$\underline{\text { Injection cannula placement }}$
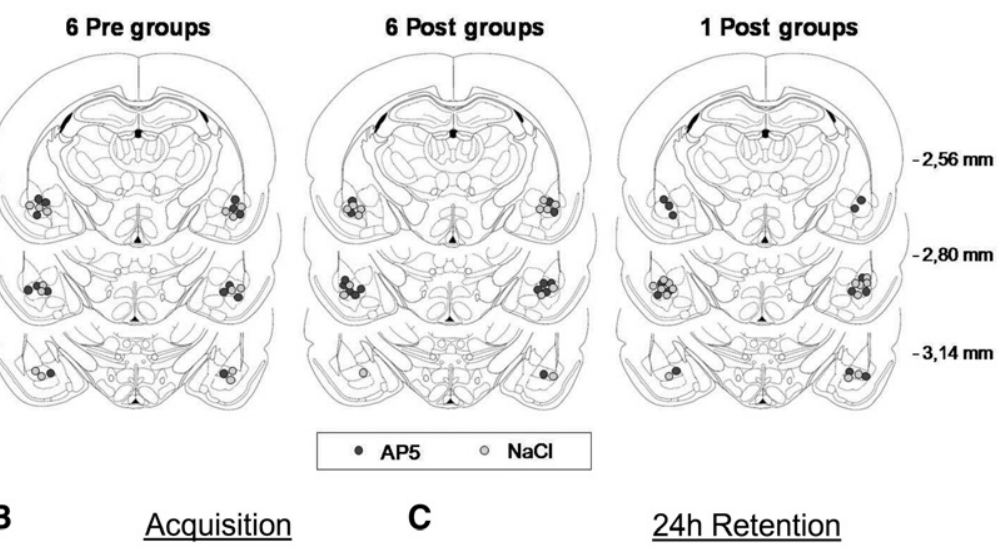

C

24h Retention
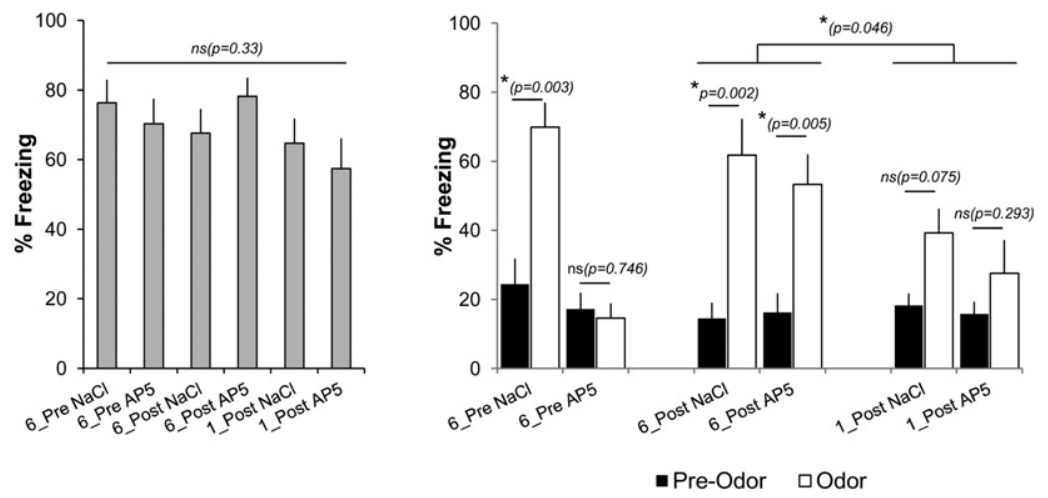

Figure 1. Effects of NMDA receptors blockade in basolateral amygdala (BLA) at different moments of the odor fear acquisition session. AP5 or $\mathrm{NaCl}$ was injected in the BLA either before (Pre groups) or after (Post groups) the first odor-shock pairing. (A) Histological verification of injection cannula placement in BLA of $\mathrm{NaCl}$ (empty circles) and AP5 (gray circles) injected animals in the different experimental groups (see Materials and Methods for details). (B) Post-shock freezing in the six experimental groups during the acquisition session. (C) Freezing during the 24-h retention test. In each group, freezing was measured before (Pre-Odor) and during (Odor) learned odor presentation. 
A

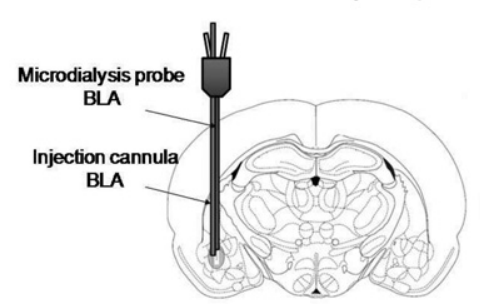

Microdialysis probe and cannula placement
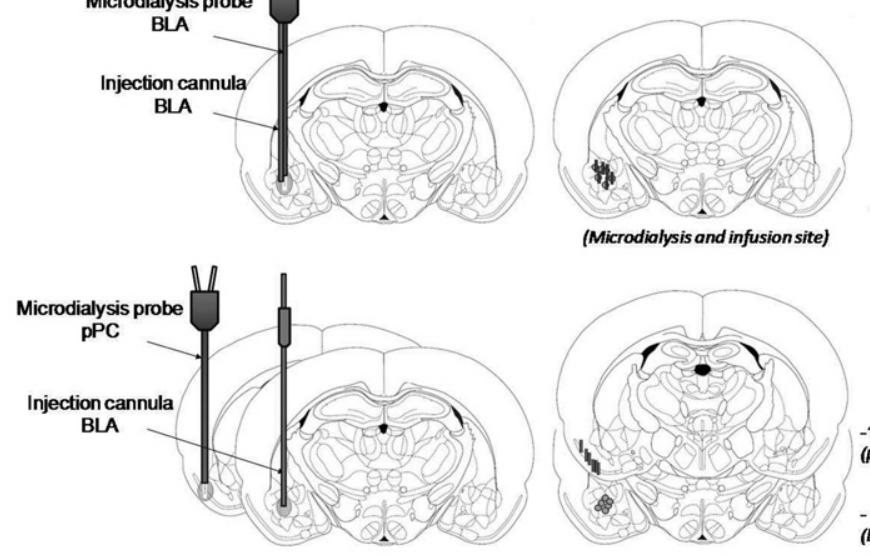

$-2,80 \mathrm{~mm}$
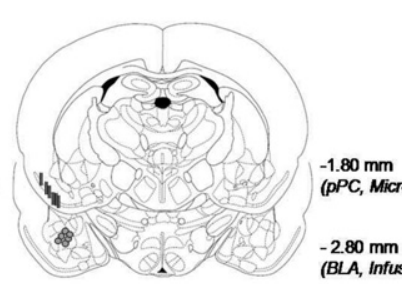

$-2.80 \mathrm{~mm}$ (BLA, Infusion site)

B Glutamate variations in BLA and pPC
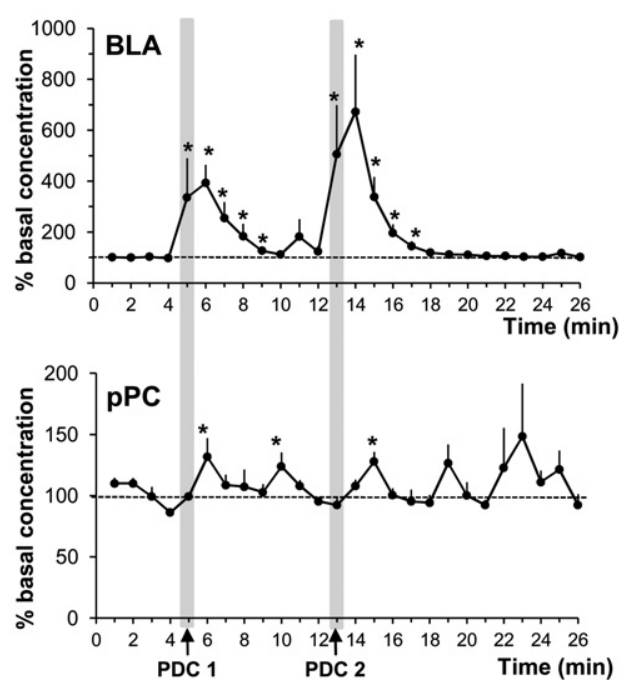

Figure 2. Effects of an artificially induced increase in glutamate in the basolateral amygdala (BLA) on glutamate levels in the posterior piriform cortex (PPC). (A) Histological verification of microdialysis probes and injection cannula placement in the BLA and PPC, in the two experimental conditions (see Materials and Methods for details). (B) Glutamate variations measured using high temporal resolution microdialysis in BLA and PPC, in response to two infusions of PDC (glutamate reuptake inhibitor) in BLA.

To summarize, PDC infusion in the BLA induced a strong and immediate local increase in glutamate, and a delayed distal increase in the $\mathrm{pPC}$.

Finally, we assessed the effects of the pretraining injection of an NMDA antagonist (AP5) in the pPC. Fourteen animals were implanted bilaterally with guide cannulae above the $\mathrm{PPC}(\mathrm{AP}-1.8$ $\mathrm{mm}$; $\mathrm{ML}+5.5 \mathrm{~mm}$; DV $-5.4 \mathrm{~mm}$ from dura); they were divided into two experimental groups. In the pPC_Pre AP5 group $(n=$ 7), AP5 was infused 1 min before the beginning of the conditioning session that included six odor-shock pairings, while in the pPC_Pre $\mathrm{NaCl}$ group $(n=7), \mathrm{NaCl}$ was infused. The animals were tested for retention at both $24 \mathrm{~h}$ and $30 \mathrm{~d}$ post-training.

Figure $3 \mathrm{~A}$ illustrates the placement of injection cannulae in pPC in the two groups. During acquisition, the amount of postshock freezing was similar in the two groups (Fig. 3B). For the retention tests performed at $24 \mathrm{~h}$ and $30 \mathrm{~d}$ (Fig. 3C), an ANOVA for repeated measures was carried out with Drug (AP5 versus $\mathrm{NaCl}$ ) as independent factor and Period (Pre-Odor versus Odor) and Test ( $24 \mathrm{~h}$ versus $30 \mathrm{~d}$ ) as repeated measures. A significant effect was found for Drug $\left(F_{(1,12)}=6.63\right.$, $P=0.024)$ and Period $\left(F_{(1,12)}=25.02\right.$, $P<0.0001)$ and a close to significant Period $\times$ Test interaction was obtained $\left(F_{(1,12)}=3.60, P=0.08\right)$, while the other interactions were not significant. Interestingly, the tendency for Period $\times$ Test interaction was increased when comparisons were restricted to the AP5 group $\left(F_{(1,6)}=5.30, P=0.06\right)$ but not to the $\mathrm{NaCl}$ group $\left(F_{(1,6)}=0.45, P=0.53\right)$. Indeed, in the AP5 group, the Period effect (i.e., higher freezing levels during the CS Odor than before) was significant at the recent test $\left(F_{(1,6)}=56.85, P<0.001\right)$ but not at the remote one $\left(F_{(1,6)}=0.35\right.$, $P=0.58)$. In regard to the Drug effect obtained in the global ANOVA, significant differences were found when the comparisons were restricted to the remote test (Fig. 3C, right part; $F_{(1,12)}=4.92$, $P=0.046$; with nonsignificant Period $\times$ Drug interaction) but not to the recent one (Fig. 3C, left part; $F_{(1,12)}=0.44, P=$ 0.52 ) indicating that the levels of freezing of AP5 animals at the 30-d retention test were globally lower than those of $\mathrm{NaCl}$ animals. Finally, pre-CS freezing significantly increased between the $24 \mathrm{~h}$ and the $30 \mathrm{~d}$ tests $\left(F_{(1,12)}=6.21\right.$, $P=0.03$ ) irrespective of the group (Drug $F_{(1,12)}=0.66, P=0.43$; Drug $\times$ Test interaction $\left.\quad F_{(1,12)}=0.0421, \quad P=0.85\right)$, which could reflect some contextual fear generalization with the passage of time (Wiltgen and Silva 2007; Winocur et al. 2007). Taken together these data suggest that there is a tendency for AP5 animals to exhibit lower remote memory performance. However, the absence of significant Drug $\times$ Period $\times$ Test interaction does not allow us to unambiguously conclude that the AP5 treatment has no effect on recent memory but impairs remote memory.

This work was aimed at investigating the involvement of NMDA receptors transmission in amygdala and cortical networks at the time of encoding on the acquisition and long-term storage of fear memories. We first showed that NMDA receptor transmission in BLA is critically involved in odor fear acquisition, mainly during the first association. Numerous studies have shown that pretraining blockade of NMDA receptors in the amygdala disrupts fear acquisition (for reviews, see Walker and Davis 2002; Rodrigues et al. 2004; Pape and Pare 2010). Our data bring new information concerning the precise time of NMDA receptors involvement. Indeed, while previous studies have targeted the acquisition session as a whole, here we highlighted the specific role of the first trial of the session. Specifically, we showed that blockade of NMDA receptors after the first pairing of a session of six pairings induced no deficit in the learning. It could be argued that the lack of deficit observed in animals receiving AP5 in BLA after the first pairing is due to the fact that the animals have learned the association in a single 

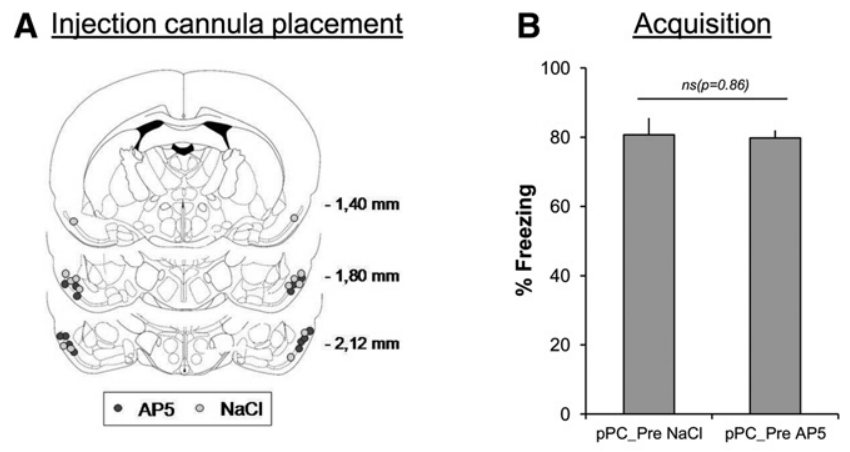

C

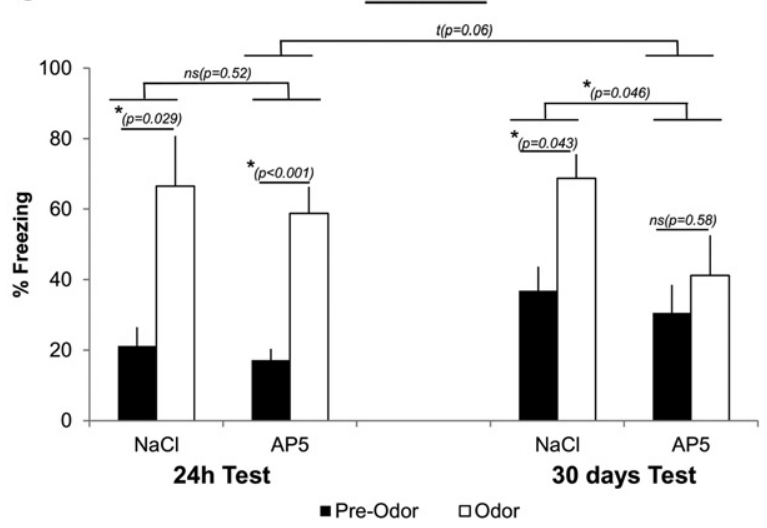

Figure 3. Effects of pretraining NMDA receptors blockade in the posterior piriform cortex (pPC) on recent (24 h) and remote (30 d) odor fear memory. (A) Histological verification of injection cannula placement in pPC of $\mathrm{NaCl}$ (empty circles) and AP5 (gray circles) injected animals in the two experimental groups (see Materials and Methods for details). (B) Post-shock freezing in the two experimental groups during the acquisition session. (C) Freezing during the 24-h- and 30-d-retention tests: Freezing was measured before (Pre-Odor) and during (Odor) learned odor presentation, in both $\mathrm{NaCl}$ and AP5 groups.

pairing (Laurent-Demir and Jaffard 2000). Here we show that the animals' performances were lower with one pairing than with six and were unaffected by AP5 treatment. Taken together these data suggest that after the first pairing, NMDA receptors are no more involved in the processing of the next pairings or in consolidation processes, comforting our previous data showing an increase in glutamate release in BLA for the first pairing but not for the next ones (Hegoburu et al. 2009). This observation is in line with previous studies showing that intra amygdala injections of NMDA antagonists carried out post-training (Maren et al. 1996; Walker and Davis 2002) or before testing (Rodrigues et al. 2001; Walker et al. 2005 in odor fear conditioning) have no effect on consolidation and expression of auditory fear conditioning. However, it is well known that the BLA is involved in memory processes occurring during or just after training and at testing (for review, see Fanselow and Gale 2003). For instance, different studies have shown increases in training-related plasticity in the BLA beyond the first trial (Quirk et al. 1995; Repa et al. 2001; Rosenkranz and Grace 2002, for odor fear conditioning). In addition, Schafe and LeDoux (2000) reported that immediate post-training infusion of anisomycin impaired fear memory retention, suggesting that BLA is essential for memory consolidation of auditory fear conditioning. Finally, AMPA-receptors-mediated fast excitatory transmission in the BLA has been shown to be involved in fear learning and fear expression (Kim et al. 1993; Walker and Davis 2002). Interestingly, recent studies showed that the amygdala is an effec- tive detector of unpredicted stimuli (Herry et al. 2007), surprising events (Klavir et al. 2013), or unexpected changes related to aversive stimuli (Diaz-Mataix et al. 2013). We therefore propose that the first odor-shock pairing (for which the surprise effect is the greatest) induces a strong increase in glutamate release, enabling NMDAR activation in BLA, which triggers the cascade of cellular events leading to long-term plasticity assumed to be involved in the maintenance of fear memory (for review, see Orsini and Maren 2012). In parallel, during the next pairings, non-NMDAdependent processes occur in the BLA, allowing further strengthening of the learning.

Our microdialysis data showed that an artificial increase in glutamate in BLA was able to trigger a glutamate increase in pPC with a 1-2 min delay. While the existence of projections from the piriform cortex to the amygdala is well known (Krettek and Price 1978; McDonald 1998), the reciprocal projection has received less attention (Majak et al. 2004). Recently, Luna and Morozov (2012) reported that the pPC differentially responds to amygdaloid versus cortical inputs by utilizing distinct local microcircuits. The pPC is thus an ideal locus to combine the sensory characteristics of the stimulus with its affective learned value transmitted by the BLA to keep the trace of this emotional olfactory memory as suggested by previous studies (Sevelinges et al. 2004, 2008, 2011; Barnes et al. 2011; Chen et al. 2011).

Most studies questioning the role of sensory cortices in fear conditioning have used auditory stimuli. These studies revealed that the lesion of auditory sensory cortices do not prevent the acquisition of auditory fear conditioning, thus arguing against their involvement in the learning (Campeau and Davis 1995; Armony et al. 1997). However, these studies have only investigated recent memory (Romanski and LeDoux 1992). Interestingly, Sacco and Sacchetti (2010) reported that excitotoxic lesions of auditory, visual, or olfactory secondary sensory cortices impaired remote, but not recent, fear memories in rats. These data show that sensory cortices are involved in the long-term storage of the sensory attributes of remote fear memories in rats. This study suggests that when NMDA receptors are blocked in pPC before training, there is a tendency toward lower remote memory performance while recent memory is unaffected. However, in contrast to Sacco and Sacchetti (2010) who described a remote memory deficit consisting of a decreased CS freezing with no change in pre-CS freezing, the deficit we observed at $30 \mathrm{~d}$ resulted from both a tendency to increased pre-CS freezing and decreased CS freezing. This lack of clear-cut effect in our experimental conditions could be due to the smaller size of our groups (7 versus 12-13) and/or the technique used (transient and more localized pharmacological blockade versus large lesion). Even if further experiments are needed to confirm the role of NMDA-dependent processes in pPC during acquisition for remote memory storage, our results clearly demonstrate that amygdala and cortical NMDA receptors activation during conditioning plays different roles in odor fear learning and memory processes.

\section{Acknowledgments}

This research was funded by the CNRS. This work was performed within the framework of the LABEX CORTEX (ANR-11-LABX0042) of Université de Lyon, within the program "Investissements d'Avenir" (ANR-11-IDEX-0007) operated by the French National Research Agency (ANR). We thank Ounsa Ben-Hellal for taking care of the animals.

\section{References}

Armony JL, Servan-Schreiber D, Romanski LM, Cohen JD, LeDoux JE. 1997. Stimulus generalization of fear responses: effects of auditory 
cortex lesions in a computational model and in rats. Cereb Cortex 7: $157-165$.

Barnes DC, Chapuis J, Chaudhury D, Wilson DA. 2011. Odor fear conditioning modifies piriform cortex local field potentials both during conditioning and during post-conditioning sleep. PLOS ONE 6: e18130.

Bert L, Parrot S, Robert F, Desvignes C, Denoroy L, Suaud-Chagny MF, Renaud B. 2002. In vivo temporal sequence of rat striatal glutamate, aspartate and dopamine efflux during apomorphine, nomifensine, NMDA and PDC in situ administration. Neuropharmacology 43: $825-835$.

Campeau S, Davis M. 1995. Involvement of subcortical and cortical afferents to the lateral nucleus of the amygdala in fear conditioning measured with fear-potentiated startle in rats trained concurrently with auditory and visual conditioned stimuli. J Neurosci 15: 2312-2327.

Chen CF, Barnes DC, Wilson DA. 2011. Generalized vs. stimulus-specific learned fear differentially modifies stimulus encoding in primary sensory cortex of awake rats. J Neurophysiol 106: 3136-3144.

Diaz-Mataix L, Ruiz Martinez RC, Schafe GE, LeDoux JE, Doyere V. 2013. Detection of a temporal error triggers reconsolidation of amygdala-dependent memories. Curr Biol 23: 467-472.

Fanselow MS, Gale GD. 2003. The amygdala, fear, and memory. Ann N Y Acad Sci 985: 125-134.

Gale GD, Anagnostaras SG, Godsil BP, Mitchell S, Nozawa T, Sage JR, Wiltgen B, Fanselow MS. 2004. Role of the basolateral amygdala in the storage of fear memories across the adult lifetime of rats. J Neurosci 24: $3810-3815$.

Hegoburu C, Sevelinges Y, Thevenet M, Gervais R, Parrot S, Mouly AM. 2009. Differential dynamics of amino acid release in the amygdala and olfactory cortex during odor fear acquisition as revealed with simultaneous high temporal resolution microdialysis. Learn Mem 16: 687-697.

Hegoburu C, Shionoya K, Garcia S, Messaoudi B, Thevenet M, Mouly AM. 2011. The RUB cage: respiration-ultrasonic vocalizations-behavior acquisition setup for assessing emotional memory in rats. Front Behav Neurosci 5: 25.

Herry C, Bach DR, Esposito F, Di Salle F, Perrig WJ, Scheffler K, Luthi A, Seifritz E. 2007. Processing of temporal unpredictability in human and animal amygdala. J Neurosci 27: 5958-5966.

Kim M, Campeau S, Falls WA, Davis M. 1993. Infusion of the non-NMDA receptor antagonist CNQX into the amygdala blocks the expression of fear-potentiated startle. Behav Neural Biol 59: 5-8.

Klavir O, Genud-Gabai R, Paz R. 2013. Functional connectivity between amygdala and cingulate cortex for adaptive aversive learning. Neuron 80: $1290-1300$.

Krettek JE, Price JL. 1978. A description of the amygdaloid complex in the rat and cat with observations on intra-amygdaloid axonal connections. J Comp Neurol 178: 255-280.

Laurent-Demir C, Jaffard R. 2000. Paradoxical facilitatory effect of fornix lesions on acquisition of contextual fear conditioning in mice. Behav Brain Res 107: 85-91.

LeDoux JE. 2000. Emotion circuits in the brain. Annu Rev Neurosci 23: $155-184$.

Lesburguères E, Gobbo OL, Alaux-Cantin S, Hambucken A, Trifilieff P, Bontempi B. 2011. Early tagging of cortical networks is required for the formation of enduring associative memory. Science 331: 924-928.

Luna VM, Morozov A. 2012. Input-specific excitation of olfactory cortex microcircuits. Front Neural Circuits 6: 69.

Majak K, Ronkko S, Kemppainen S, Pitkanen A. 2004. Projections from the amygdaloid complex to the piriform cortex: A PHA-L study in the rat. J Comp Neurol 476: 414-428.

Maren S. 2001. Neurobiology of Pavlovian fear conditioning. Annu Rev Neurosci 24: 897-931.

Maren S, Aharonov G, Stote DL, Fanselow MS. 1996. N-methyl-D-aspartate receptors in the basolateral amygdala are required for both acquisition and expression of conditional fear in rats. Behav Neurosci 110: $1365-1374$.

McDonald AJ. 1998. Cortical pathways to the mammalian amygdala. Prog Neurobiol 55: 257-332.

Orsini CA, Maren S. 2012. Neural and cellular mechanisms of fear and extinction memory formation. Neurosci Biobehav Rev 36: $1773-1802$.

Pape HC, Pare D. 2010. Plastic synaptic networks of the amygdala for the acquisition, expression, and extinction of conditioned fear. Physiol Rev 90: $419-463$

Parrot S, Sauvinet V, Riban V, Depaulis A, Renaud B, Denoroy L. 2004. High temporal resolution for in vivo monitoring of neurotransmitters in awake epileptic rats using brain microdialysis and capillary electrophoresis with laser-induced fluorescence detection. J Neurosci Methods 140: 29-38.

Quirk GJ, Repa JC, LeDoux JE. 1995. Fear conditioning enhances short-latency auditory responses of lateral amygdala neurons: parallel recordings in the freely behaving rat. Neuron 15: 1029-1039:

Repa JC, Muller J, Apergis J, Desrochers TM, Zhou Y, LeDoux JE. 2001. Two different lateral amygdala cell populations contribute to the initiation and storage of memory. Nat Neurosci 4: 724-731.

Riedel G, Platt B, Micheau J. 2003. Glutamate receptor function in learning and memory. Behav Brain Res 140: 1-47.

Rodrigues SM, Schafe GE, LeDoux JE. 2001. Intra-amygdala blockade of the NR2B subunit of the NMDA receptor disrupts the acquisition but not the expression of fear conditioning. J Neurosci 21: 6889-6896.

Rodrigues SM, Schafe GE, LeDoux JE. 2004. Molecular mechanisms underlying emotional learning and memory in the lateral amygdala. Neuron 44: 75-91.

Romanski LM, LeDoux JE. 1992. Equipotentiality of thalamo-amygdala and thalamo-cortico-amygdala circuits in auditory fear conditioning. J Neurosci 12: 4501-4509.

Rosenkranz JA, Grace AA. 2002. Dopamine-mediated modulation of odour-evoked amygdala potentials during Pavlovian conditioning. Nature 417: 282-287.

Sacco T, Sacchetti B. 2010. Role of secondary sensory cortices in emotional memory storage and retrieval in rats. Science 329: 649-656.

Schafe GE, LeDoux JE. 2000. Memory consolidation of auditory Pavlovian fear conditioning requires protein synthesis and protein kinase $\mathrm{A}$ in the amygdala. J Neurosci 20: RC96.

Sevelinges Y, Gervais R, Messaoudi B, Granjon L, Mouly AM. 2004. Olfactory fear conditioning induces field potential potentiation in rat olfactory cortex and amygdala. Learn Mem 11: 761-769.

Sevelinges Y, Sullivan RM, Messaoudi B, Mouly AM. 2008. Neonatal odor-shock conditioning alters the neural network involved in odor fear learning at adulthood. Learn Mem 15: 649-656.

Sevelinges Y, Mouly AM, Raineki C, Moriceau S, Forest C, Sullivan RM. 2011. Adult depression-like behavior, amygdala and olfactory cortex functions are restored by odor previously paired with shock during infant's sensitive period attachment learning. Dev Cogn Neurosci 1: 77-87.

Walker DL, Davis M. 2002. The role of amygdala glutamate receptors in fear learning, fear-potentiated startle, and extinction. Pharmacol Biochem Behav 71: 379-392.

Walker DL, Paschall GY, Davis M. 2005. Glutamate receptor antagonist infusions into the basolateral and medial amygdala reveal differential contributions to olfactory vs. context fear conditioning and expression. Learn Mem 12: 120-129.

Wiltgen BJ, Silva AJ. 2007. Memory for context becomes less specific with time. Learn Mem 14: 313-317.

Winocur G, Moscovitch M, Sekeres M. 2007. Memory consolidation or transformation: context manipulation and hippocampal representations of memory. Nat Neurosci 10: 555-557.

Received July 25, 2014; accepted in revised form August 8, 2014. 


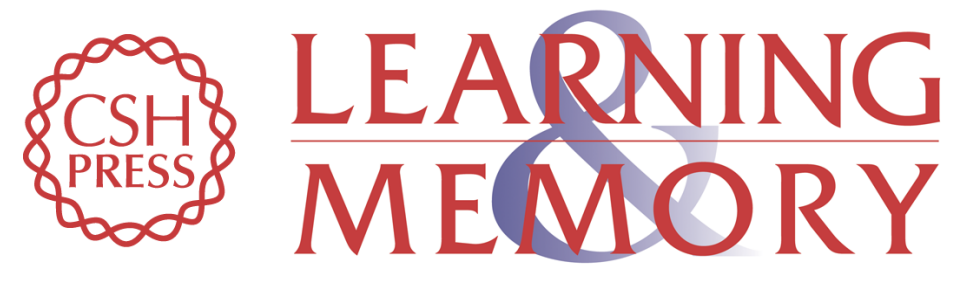

\section{Differential involvement of amygdala and cortical NMDA receptors activation upon encoding in odor fear memory}

Chloé Hegoburu, Sandrine Parrot, Guillaume Ferreira, et al.

Learn. Mem. 2014, 21:

Access the most recent version at doi:10.1101/Im.036558.114

\begin{aligned} & \hline References $\begin{array}{l}\text { This article cites } 41 \text { articles, } 13 \text { of which can be accessed free at: } \\ \text { http://learnmem.cshlp.org/content/21/12/651.full.html\#ref-list-1 }\end{array} \\ & \begin{array}{r}\text { Creative } \\ \text { Commons } \\ \text { License }\end{array} \begin{array}{l}\text { This article is distributed exclusively by Cold Spring Harbor Laboratory Press for the } \\ \text { first } 12 \text { months after the full-issue publication date (see } \\ \text { http://learnmem.cshlp.org/site/misc/terms.xhtml). After } 12 \text { months, it is available under } \\ \text { a Creative Commons License (Attribution-NonCommercial } 4.0 \text { International), as } \\ \text { described at http://creativecommons.org/licenses/by-nc/4.0/. }\end{array} \\ & \begin{array}{c}\text { Receive free email alerts when new articles cite this article - sign up in the box at the } \\ \text { top right corner of the article or click here. }\end{array} \\ & \begin{array}{c}\text { Service } \\ \text { terting }\end{array}\end{aligned}$

